\title{
Endoscopic Management of Gastroesophageal Reflux Disease: Revisited
}

\author{
Zaheer Nabi and D. Nageshwar Reddy \\ Asian Institute of Gastroenterology, Hyderabad, India
}

Gastroesophageal reflux disease (GERD) is defined by the presence of troublesome symptoms resulting from the reflux of gastric contents. The prevalence of GERD is increasing globally. An incompetent lower esophageal sphincter underlies the pathogenesis of GERD. Proton pump inhibitors (PPIs) form the core of GERD management. However, a substantial number of patients do not respond well to PPIs. The next option is anti-reflux surgery, which is efficacious, but it has its own limitations, such as gas bloating, inability to belch or vomit, and dysphagia. Laparoscopic placement of magnetic augmentation device is emerging as a useful alternative to conventional anti-reflux surgery. However, invasiveness of a surgical procedure remains a concern for the patients. The proportion of PPI non-responders or partial responders who do not wish for anti-reflux surgery defines the 'treatment gap' and needs to be addressed. The last decade has witnessed the fall and rise of many endoscopic devices for GERD. Major endoscopic strategies include radiofrequency ablation and endoscopic fundoplication devices. Current endoscopic devices score high on subjective improvement, but have been unimpressive in objective improvement like esophageal acid exposure. In this review, we discuss the current endoscopic antireflux therapies and available evidence for their role in the management of GERD. Clin Endosc 2016;49:408-416

Key Words: Endoscopy; Gastroesophageal reflux; Fundoplication; Catheter ablation; Surgery

\section{INTRODUCTION}

The incidence of gastroesophageal reflux disease (GERD) is increasing. ${ }^{1}$ The true incidence of GERD may be underestimated because of the use of over-the-counter medications, such as antacids and proton pump inhibitors (PPIs). GERD not only adversely affects the patient's quality of life, but it is also a potential risk factor for the development of Barrett's esophagus and esophageal adenocarcinoma. ${ }^{1}$

PPIs have been the mainstay of medical management of GERD. However, about $20 \%$ to $30 \%$ of patients with erosive reflux disease and $40 \%$ of patients with non-erosive reflux disease do not respond to PPIs. Moreover, no significant im-

Received: September 7, 2016 Revised: September 19, 2016

Accepted: September 19, 2016

Correspondence: D. Nageshwar Reddy

Asian Institute of Gastroenterology, 6-3-661, Somajiguda, Hyderadad, India Tel: +91-40-2337-8888, Fax: +91-40-2332-4255, E-mail: aigindia@yahoo.co.in

(cc) This is an Open Access article distributed under the terms of the Creative Commons Attribution Non-Commercial License (http://creativecommons.org/ licenses/by-nc/3.0) which permits unrestricted non-commercial use, distribution, and reproduction in any medium, provided the original work is properly cited. provement is observed in symptoms with doubling the dose of PPIs. ${ }^{2}$ The potential adverse effects of using PPIs for long term are also a matter of concern. These adverse effects include Clostridium difficile infection, bone fractures, hypomagnesemia, and higher incidence of chronic kidney disease in susceptible populations. ${ }^{3-5}$

Anti-reflux surgery (ARS: open or laparoscopic fundoplication) has been the mainstay of treatment for patients not responsive to PPIs and documented reflux on $\mathrm{pH}$-impedance analysis. However, a quarter of patients restart PPIs on longterm follow-up. Moreover, a requirement of re-intervention exists in about $15 \%$ and $30 \%$ patients after laparoscopic or conventional fundoplication, respectively. ${ }^{6}$ Other adverse events known to occur with ARS include dysphagia, gas bloating, and inability to belch. ${ }^{7}$ Patients with refractory GERD may not agree to ARS due to its invasive nature and possible adverse events as mentioned above. In a randomized controlled trial (RCT) comparing ARS with PPIs, the remission rates were similar in both arms at 5-year follow-up. However, adverse events, including gas bloating, dysphagia, and flatulence, were significantly higher in the ARS arm. 


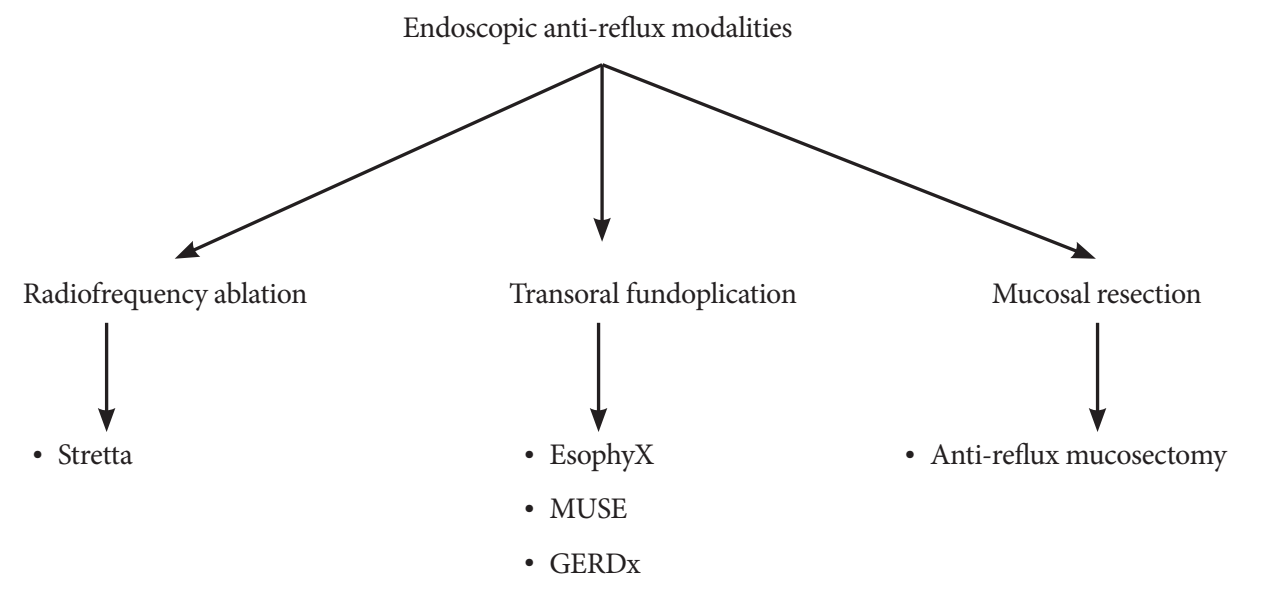

Fig. 1. Currently available endoscopic anti-reflux modalities. Stretta (Mederi Therapeutics), EsophyX (EndoGastric Solutions), MUSE (Medigus), GERDx (G-SURG GmbH).
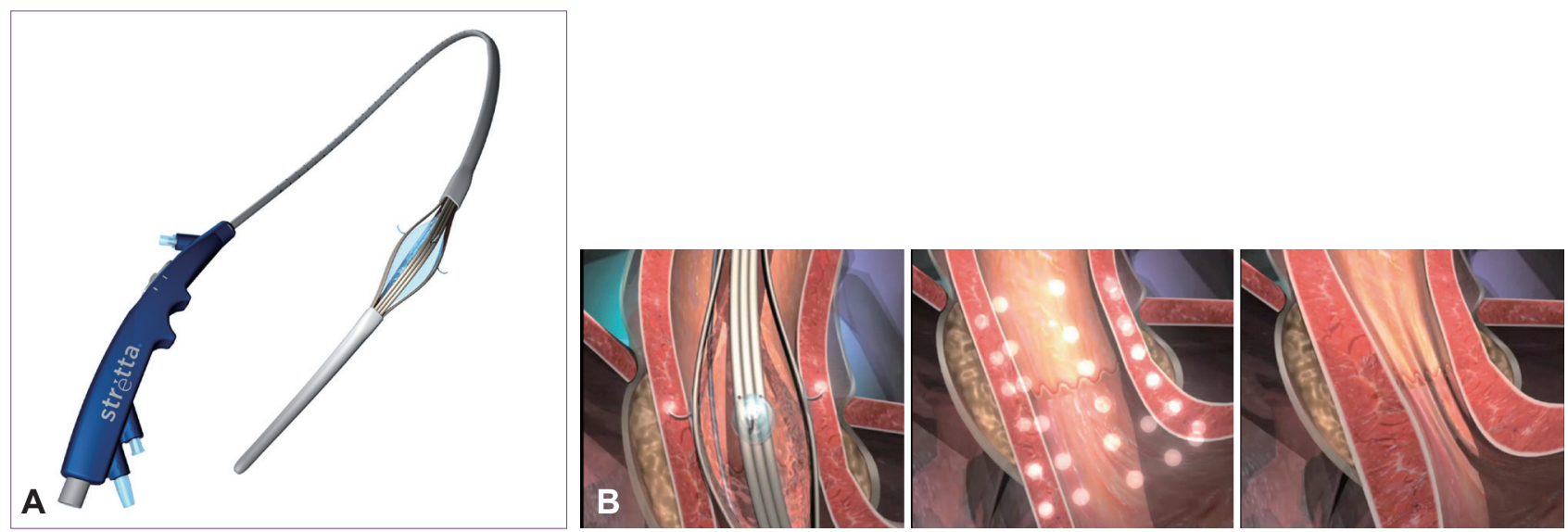

Fig. 2. (A) Radiofrequency device (Stretta; Mederi Therapeutics) with a four-needle balloon catheter system. (B) Depiction of Stretta procedure-radiofrequency energy delivered to gastroesophageal junction muscle at multiple sites.

Laparoscopic fundoplication was the only surgical option for GERD until recently. The introduction of magnetic sphincter augmentation (MSA) has marked the beginning of a new era in the surgical management of these patients. MSA device (LINX System; Torax Medical Inc., Shoreview, MN, USA) consists of a small flexible band of interlinked titanium beads with magnetic cores. It is placed laparoscopically around the lower esophageal sphincter (LES) without altering hiatal or gastric anatomy. The beads separate during swallowing as well as during belching or vomiting. ${ }^{9}$ Therefore, adverse events, such as dysphagia, inability to belch, and vomiting, are less frequent as compared to the traditional ARS. A published literature suggests that MSA is equally effective with less procedure duration as compared to ARS. ${ }^{10}$ The most common adverse event with MSA procedure is dysphagia for which the device may have to be removed in some patients. Recently, a case of endoluminal perforation has been reported with MSA resulting in severe dysphagia. ${ }^{11}$

With the increasing prevalence of GERD, there is an unmet need for minimally invasive treatment modalities for patients who do not respond to PPIs and are unwilling for ARS. Min- imally invasive endoscopic options for GERD have been in place for more than a decade now. Some of these have not stood the test of time either due to inefficacy, non-durable response, or safety issues. These include implantation and injection devices (Enteryx [Boston Scientific Corp, Natick, MA, USA], Gatekeeper [Medtronic, Minneapolis, MN, USA], Plexiglas microspheres [Artes Medical, San Diego, CA, USA]) and several endoscopic apposition devices (EndoCinch [Bard Medical, Covington, GA USA], NDO Plicator [NDO Surgical, Mansfield, MA, USA]). The currently available endoscopic anti-reflux modalities (EARMs) include radiofrequency ablation (RFA), transoral incisionless fundoplication (TIF), medigus ultrasonic surgical endostapler (MUSE), and anti-reflux mucosectomy (ARMS) (Fig. 1).

\section{RADIOFREQUENCY ABLATION}

The Stretta system (Mederi Therapeutics, Norwalk, CT, USA) uses application of radiofrequency energy via a needle balloon catheter system to the LES muscle and gastric cardia (Fig. 2A). 
Multiple applications (up to 14) are given by changing the position of the balloon catheter assembly using catheter rotation and by changing its linear position in relation to the $\mathrm{Z}$ line (Fig. $2 \mathrm{~B})$. The system typically delivers low power (5 W) energy with a thermocouple that ensures avoidance of high temperatures at muscularis $\left(>85^{\circ} \mathrm{C}\right)$ and mucosal levels $\left(>50^{\circ} \mathrm{C}\right)$. In addition, regular irrigation prevents any injury to the mucosa.

The mechanism of action is not completely elucidated. The proposed mechanisms include hypertrophy of the muscularis propria and reduced transient LES relaxations after RFA. ${ }^{12,13}$ Fibrosis at the gastroesophageal junction (GEJ) was considered as one of the modes of action. However, in a recent study, reduced GEJ compliance was found after RFA, which normalized on administration of sildenafil (smooth muscle relaxant), suggesting against the development of GEJ fibrosis after RFA. $^{14}$

The efficacy and durability of response with RFA in patients with GERD are evident by multiple RCTs and a systemic review. ${ }^{15-20}$ In a long-term follow-up study, normalization of GERD health-related quality of life (GERD-HRQL) was achieved in $72 \%$ and $50 \%$ or greater reduction in PPI use occurred in $64 \%$ of patients at 10-year follow-up. Importantly, regression of Barrett's metaplasia was observed in $85 \%$ of biopsied patients. ${ }^{19}$

In a systemic review including 1,441 patients from 18 studies, RFA therapy significantly improved heartburn scores and GERD-HRQL. Esophageal acid exposure time (EAET) decreased from a pre-procedure De-Meester score of 44.4 to $28.5(p=0.007))^{20}$ The guidelines by the Society of American Gastrointestinal and Endoscopic Surgeons advocate the use of RFA in selected patients with GERD. ${ }^{21}$

In contrast to the above literature, more recently published systemic review and meta-analyses, which included four RCTs, showed no difference between Stretta versus sham or PPIs in patients with GERD for the outcomes of EAET, LES pressure, ability to stop PPIs, or HRQL. ${ }^{22}$ However, one of the criteria for efficacy in this review was normalization of $\mathrm{pH}(\mathrm{pH}<4$ exposure time $<4 \%$ ), which is rather stringent and not achieved even in patients who respond successfully to PPIs. ${ }^{23}$ Moreover, the authors agree that the overall quality of evidence from RCTs on the efficacy of the Stretta procedure was extremely low.
There are few comparative studies between RFA and ARS (laparoscopic Toupet fundoplication) with contradictory results. In a prospective observational study, ARS and the Stretta procedure were equally effective in controlling GERD symptoms and reducing the use of PPIs. ${ }^{24}$ In another study, the Stretta procedure was equal to ARS in controlling extraesophageal manifestations of GERD. ${ }^{25}$ By contrast, Stretta was inferior to ARS for typical and respiratory symptoms associated with GERD in two other studies. ${ }^{26,27}$ Unfortunately, no RCTs to date have compared both the modalities.

One of the major advantages of Stretta over other EARMs is that it can be performed under conscious sedation as a day care procedure. Moreover, the procedure duration is short, and its safety and efficacy have been studied more than in any other EARMs. It also does not hinder subsequent therapy like ARS if required. The major drawbacks of RFA are the wide variability in response rates (16\% to $86 \%)$ and the low rate of improvement in objective parameters like normalization of EAET ${ }^{18}$ Complete cessation of PPI use is achieved in only $40 \%$ of patients on long-term follow-up..$^{19}$ Patients with large hiatal hernia and severe esophagitis are not ideal candidates for RFA.

Adverse events noted with RFA therapy are usually mild and include chest pain (50\%), transient fever, and esophageal ulcers. Gastroparesis has been rarely reported presumably due to inadvertent vagal nerve injury. ${ }^{28}$

\section{TRANSORAL INCISIONLESS FUNDOPLICATION}

The TIF procedure is a minimally invasive treatment for GERD and follows the principles of ARS, i.e., by reducing a hiatal hernia $(\leq 2 \mathrm{~cm})$ and creating a valve 2 to $4 \mathrm{~cm}$ in length and greater than $270^{\circ}$ circumferential wrap. It is performed in the outpatient setting under general anesthesia. The TIF procedure has undergone several modifications since its introduction about a decade ago (Table 1). In this procedure, a fundoplication device (EsophyX; EndoGastric Solutions, Redmond, WA, USA) (Fig. 3A) is used with a flexible endoscope and gently introduced into the stomach under visualization (Fig. 3B). The endoscope along with the device is retroflexed,

Table 1. The Evolution of the Transoral Incisionless Fundoplication

\begin{tabular}{lccc}
\hline Name & Fastener placement & Plication type & Wrap \\
\hline Endoluminal fundoplication & Below Z line & Gastrogastric & No \\
Transoral incisionless iundoplication 1.0 & Above Z line $1 \mathrm{~cm}$ & Esophagogastric & No \\
Transoral incisionless fundoplication 2.0 & $\begin{array}{c}1-3 \mathrm{~cm} \text { above Z line; more length } \\
\text { along greater curve of the stomach }\end{array}$ & Esophagogastric & Yes \\
\hline
\end{tabular}




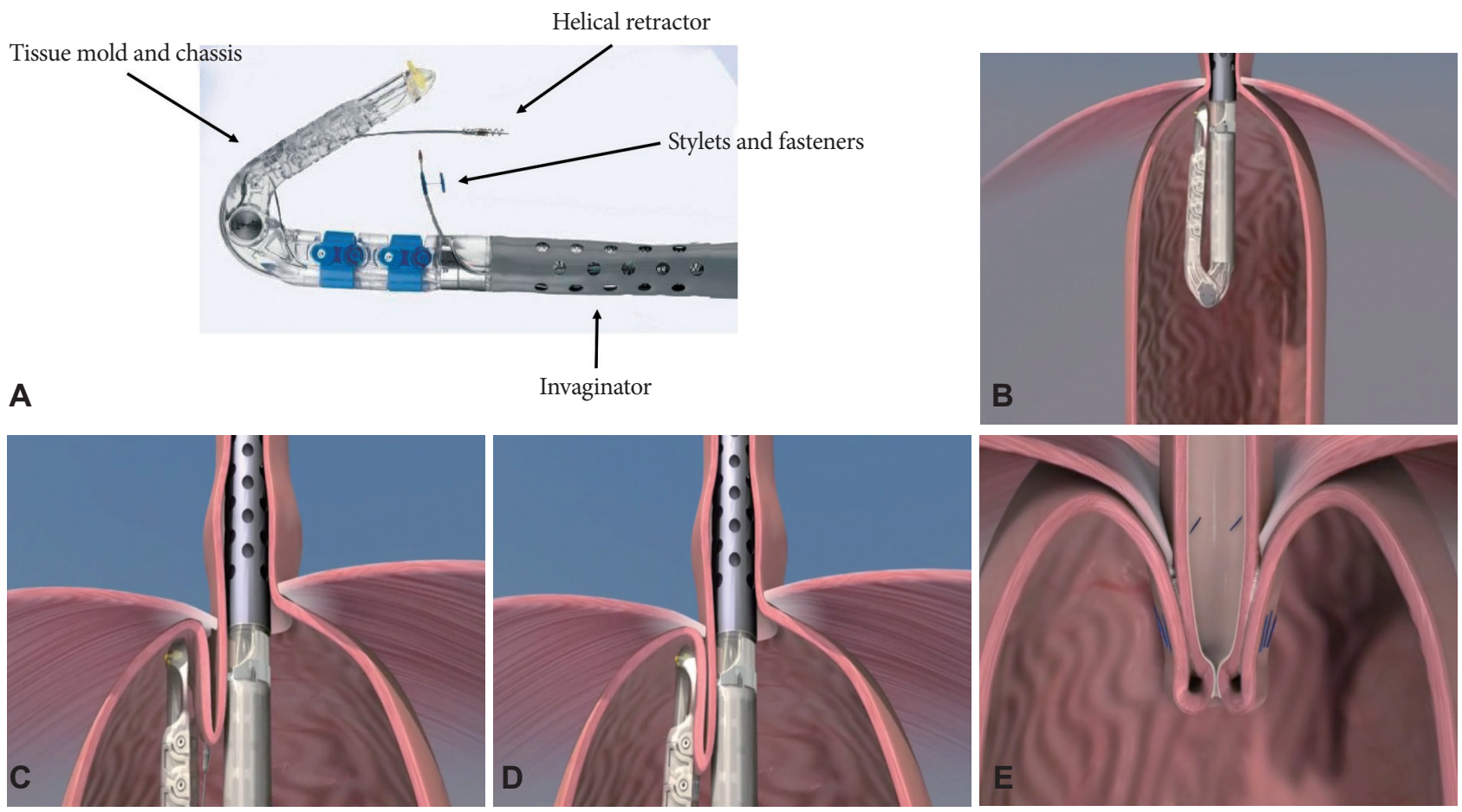

Fig. 3. (A) Transoral fundoplication device (EsophyX; EndoGastric Solutions) and its components. (B) Retroflexed device in the stomach. (C) Engaging the helical retractor into the tissue. (D) Application of H-shaped polypropylene fasteners (about 20). (E) Creation of full-thickness partial circumference fundoplication.

and a helical retractor is engaged into the tissue slightly distal to the $\mathrm{Z}$ line (Fig. 3C). The fundus of the stomach is folded up and around the distal esophagus utilizing the tissue mold and chassis of the device. Subsequently, an integrated suction apparatus grasps the distal esophagus and positions it below the diaphragm. H-shaped fasteners, made of polypropylene, are then delivered through apposed layers of esophageal and fundus tissue to anchor the repair. This process is repeated to create a full thickness, partial circumference, and gastroesophageal fundoplication (Fig. 3D, E). Approximately 20 fasteners are implanted during the procedure to create fusion of the esophageal and fundus tissues and form the valve.

Multiple studies including five RCTs and two systemic reviews have shown the efficacy of TIF. $^{29-34}$ In a systemic review including 963 patients from 18 studies (five RCTs and 13 prospective observational), the pooled relative risk of response rate to TIF versus PPIs/sham was 2.44 (95\% confidence interval, 1.25 to $4.79 ; p=0.0009$ ) in RCTs in the intention-to-treat analysis. The total number of refluxes was reduced after TIF compared with the PPIs/sham group. However, the EAET and acid reflux episodes were not significantly improved, and PPI usage increased with time during the long-term follow-up. The incidence of severe adverse events consisting of gastrointestinal perforation and bleeding was $2.4 \%{ }^{34}$

The durability of response is evident in a recent study with a 6-year follow-up. PPIs were stopped or halved in $87.8 \%$ and
$84.4 \%$ at 2 and 3 years, respectively, with stable response up to 6 years. $^{35}$

One study compared TIF with ARS (Nissen and Toupet fundoplication). Both groups showed similar reduction in symptom frequency and severity. However, patients undergoing TIF exhibited significantly shorter operative times and length of stay. ${ }^{36}$

The factors predicting good outcome with TIF include pre-procedure Hill grade I to II, no or small hiatal hernia $(\leq 2 \mathrm{~cm})$, normal esophageal motility, number of fasteners deployed, persistence of typical symptoms on PPIs (GERD HRQL score $\geq 15$ ), and an objectively confirmed diagnosis of GERD. $^{35,37}$

The advantages of TIF are that it is less invasive than ARS, is performed in outpatient settings, has fewer adverse effects, and does not preclude the chances of revision ARS if required ${ }^{38}$ Serious adverse events reported with TIF are rare and include perforation, pneumothorax, and bleeding. ${ }^{39}$

With respect to symptom response and safety profile, TIF appears promising. However, normalization of EAET and complete cessation of PPIs are not achieved in long-term follow-up studies. In one study, only one-third of patients were completely off PPIs at 6-year follow-up. ${ }^{35}$ 


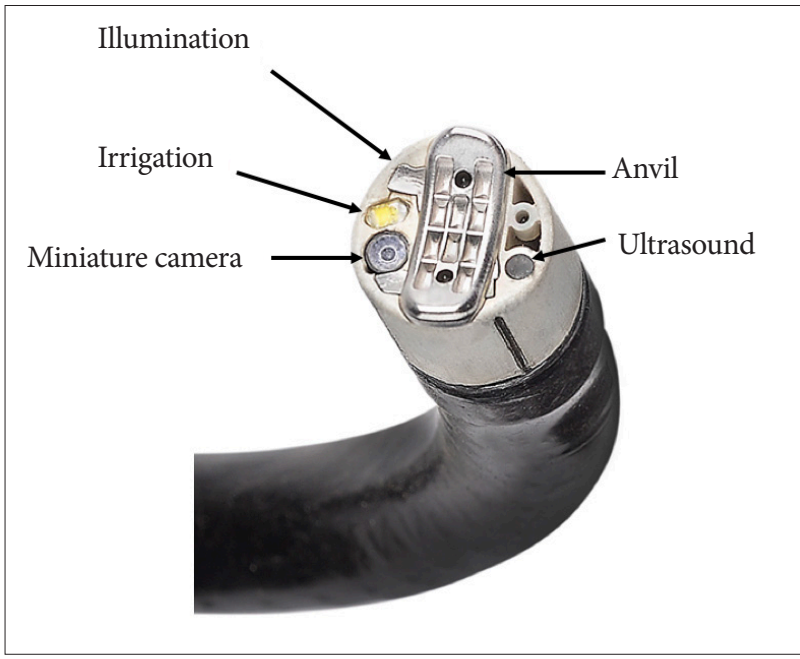

Fig. 4. MUSE (Medigus) endoscopic stapling device and its components.

\section{MEDIGUS ULTRASONIC SURGICAL ENDOSTAPLER}

The MUSE (Medigus, Omer, Israel) is an endoscopic stapling device for transoral partial fundoplication. The complete device consists of a flexible endoscope, an endostapler, a video camera, and an ultrasound transducer (Fig. 4). After inserting the device, retroflexion is performed in the stomach, and the device is withdrawn until the chosen stapling level (usually $3 \mathrm{~cm}$ above the $\mathrm{Z}$ line). Subsequently, the stapler is fired under the guidance of ultrasonic gap finder. The process is repeated to form a flap akin to laparoscopic fundoplication.

In a multicenter study including 66 patients, significant improvement in GERD-HRQL score was found in $73 \%$ of patients at 6 months after the procedure. About $65 \%$ of patients completely discontinued PPIs, and significant reduction in PPI dosage was observed in $56 \%$ of patients who still continued PPIs. EAET also reduced at 6 months. ${ }^{40}$

Two severe adverse events including empyema/pneumothorax and upper gastrointestinal hemorrhage occurred in initial 24 subjects. The technique and device were then modified, and no serious adverse events were noted in subsequent patients.

Long-term results with this device have been published recently. In a long-term follow-up study, 69.4\% were off PPIs at 4 years after the TIF procedure. A significant reduction in GERDHRQL scores and the daily dosage of GERD medications was found. $^{41}$

Although emerging data with MUSE is encouraging, it is a relatively new procedure with limited long-term data on efficacy and safety. The ideal stapling site for this procedure is also not well known. An ex vivo study concluded that the ideal stapling site was at $3 \mathrm{~cm}$ above the GEJ. ${ }^{42}$ However, the results need to be interpreted with caution as it is an ex vivo study.

\section{ENDOSCOPIC FULL THICKNESS PLICATION (GERx)}

Initial studies of endoscopic full thickness plication (EFTP) were carried out with the Plicator device (Ethicon Endosurgery, Somerville, NJ, USA). However, this device is no longer available commercially. Recently, a new device based on plicator technology and produced by a different manufacturer has been introduced (GERDx System; G-SURG GmbH, Seeon-Seebruck, Germany) (Fig. 5).

The procedure of EFTP itself has undergone several modifications since its initial introduction for GERD. A single suture was initially placed below GEJ. However, the results were not impressive as a single suture could not create an effective anti-reflux barrier. ${ }^{43}$ Subsequently, the technique was modified, and multiple plication implants were placed to achieve a robust antireflux valve. ${ }^{44-46}$

In a prospective study including 36 patients, symptoms improved in $92 \%$ and $89 \%$ of patients were off PPIs at 1-year follow-up after EFTP with one or more plication implants. There was also a significant reduction in EAET. ${ }^{44}$ Similar results were produced in a multicenter study, where $75 \%$ of patients had $>50 \%$ improvement in GERD-HRQL and $70 \%$ of patients were off daily PPIs at 6 months. The subjective improvement and elimination of need for daily PPI usage persisted at 1-year follow-up. ${ }^{45,46}$ Postprocedure adverse events were minor and included pain in the abdomen, shoulder, and chest. There were no long-term adverse events.

\section{ANTI-REFLUX MUCOSECTOMY}

The ARMS procedure is based on the principle that after mucosal resection, the mucosal healing results in scar formation. This in turn results in shrinkage and remodeling of gastric cardia flap valve; thereby, reducing reflux events. Although the first case was performed more than a decade ago, the results of the first series were published recently. ${ }^{47,48}$

The technique of ARMS procedure (as described by Inoue et $\mathrm{al}^{48}$ ) involves resection of gastric (about $2 \mathrm{~cm}$ ) and esophageal mucosa (about $1 \mathrm{~cm}$ ) in crescentic fashion. The field of resection is initially marked by an electrocautery knife. Subsequently, a solution of saline mixed with indigo-carmine dye is injected submucosally to raise a wheal (Fig. 6A). In the next step, mucosal resection is performed along the lesser curvature either by endoscopic mucosal resection or submucosal dissection (Fig. 6B, C). A gap equal to twice the scope 

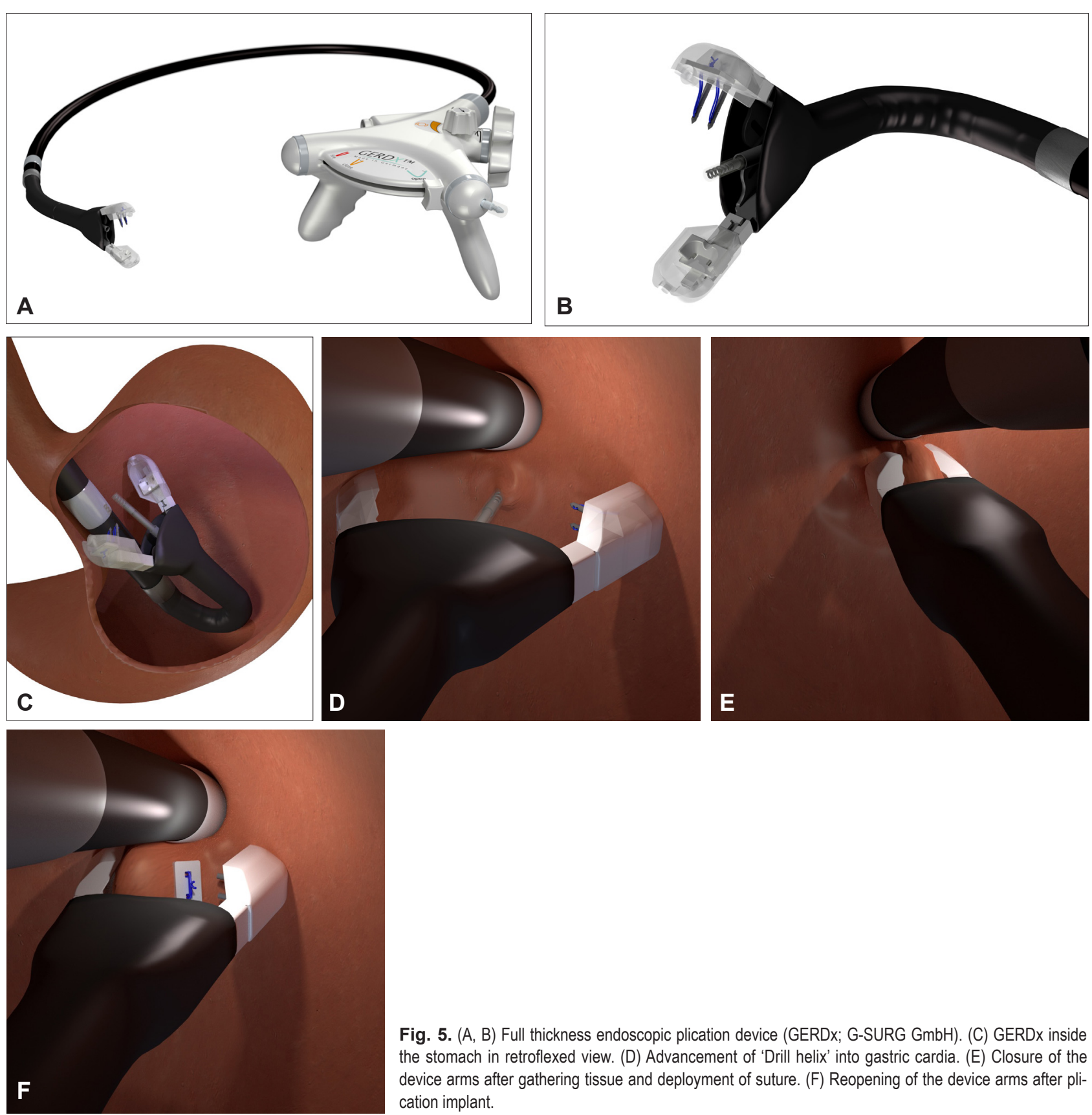

Fig. 5. (A, B) Full thickness endoscopic plication device (GERDx; G-SURG GmbH). (C) GERDx inside the stomach in retroflexed view. (D) Advancement of 'Drill helix' into gastric cardia. (E) Closure of the device arms after gathering tissue and deployment of suture. (F) Reopening of the device arms after plication implant.

diameter is left along the greater curvature side. Circumferential resection of the mucosa is avoided to prevent stricture formation as was noted in initial few cases of this series. Any bleeding during the procedure is controlled by coagrasper (Fig. $6 \mathrm{D}, \mathrm{E})$. In the only published pilot study including 10 patients, there was reduction in EAET and improvement in flap valve grade observed on endoscopic examination. In addition, all the patients could discontinue PPI after the ARMS therapy. ${ }^{47}$

The advantages of ARMS include no requirement of any propriety devices and no endoprostheses are left in situ. However, no randomized studies have been conducted, and dura- bility of response is unknown. In addition, the amount of mucosa to be resected for optimal results is not known and needs further evaluation. As with other EARMs, patients with large hiatal hernia are not suitable candidates for ARMS procedure.

\section{EARMs: THE PROS AND CONS}

EARMs are emerging as minimally invasive treatment option for patients with GERD. Reduced hospital stay and adverse events were observed compared with the conven- 

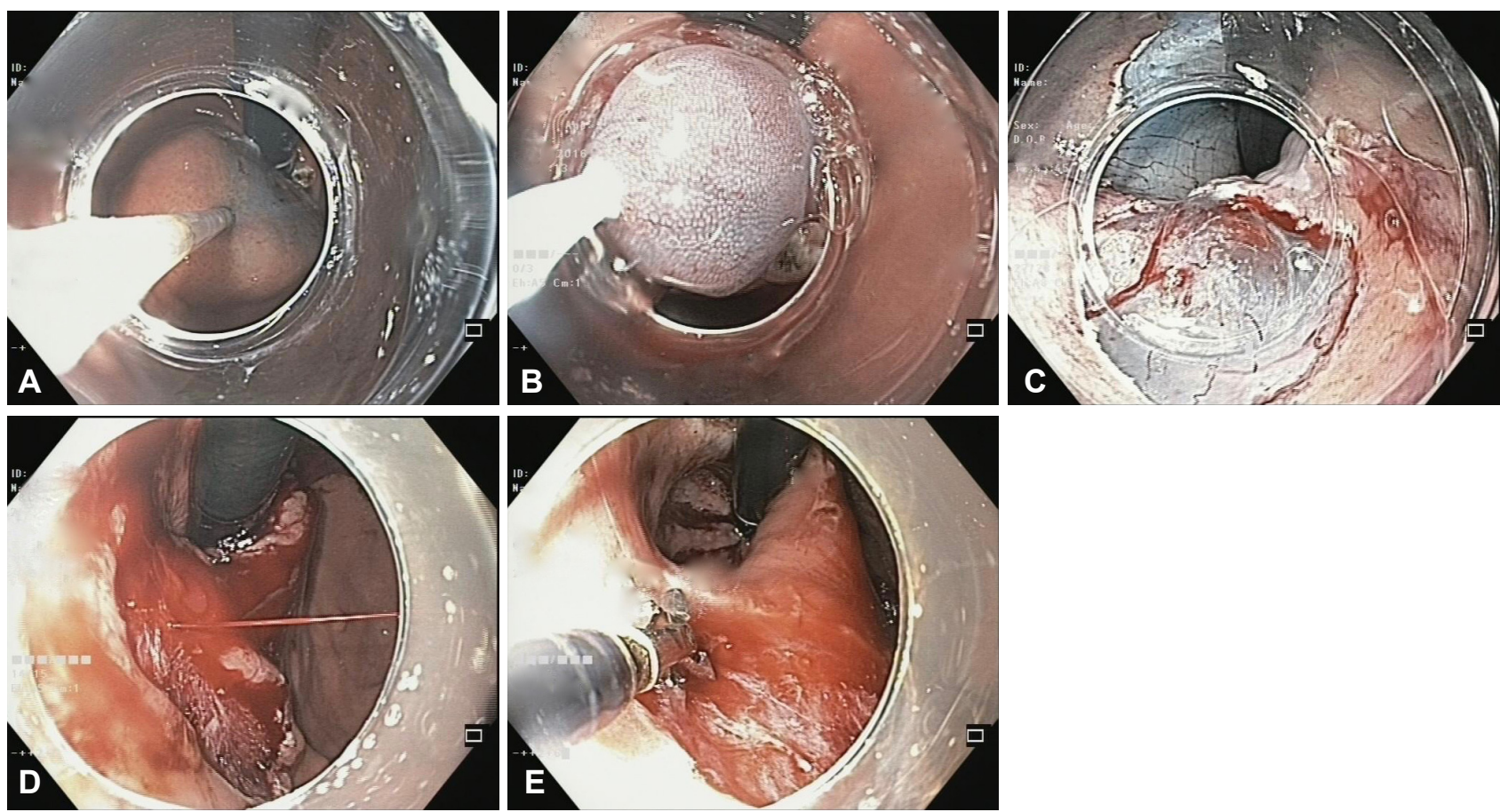

Fig. 6. (A) Submucosal injection of saline with indigo-carmine at gastric cardia. (B) Application of snare over the mucosa with cap-endoscopic mucosal resection technique. (C) Completion of near circumferential (2/3) resection of gastric mucosa. (D) Actively bleeding spurter during mucosectomy procedure. (E) Effective control of bleeding vessel with coagrasper.

Table 2. Comparison of Available Endoscopic Antireflux Therapies

\begin{tabular}{lccc}
\hline Variable & Stretta & TIF & MUSE \\
\hline $\begin{array}{l}\text { Treatment response (complete } \\
\text { cessation of PPI) }\end{array}$ & $16 \%-80 \%^{14,15}$ & $32 \%-82 \%^{34}$ & $65 \%^{\mathrm{a})}-83.8 \%^{\mathrm{b}), 39,40}$ \\
$\begin{array}{l}\text { Durability of response (longest } \\
\text { follow-up) }\end{array}$ & $41 \%$ at 10 years $^{18}$ & $36 \%$ at 6 years $^{33}$ & $69 \%$ at 4 years ${ }^{\mathrm{b}), 40}$ \\
$\begin{array}{l}\text { Normalization of esophageal acid } \\
\text { exposure }\end{array}$ & $5 \%-75 \%^{14,17}$ & $37 \%-89 \%^{32}$ & $37.1 \%^{40}$ \\
Serious adverse events & $\begin{array}{c}\text { Aspiration pneumonia, } \\
\text { gastroparesis }\end{array}$ & $\begin{array}{c}\text { Bleeding, perforation, } \\
\text { pneumothorax }\end{array}$ & $\begin{array}{c}\text { Bleeding, pneumothorax, } \\
\text { pneumomediastinum }^{40}\end{array}$ \\
\hline
\end{tabular}

TIF, transoral incisionless fundoplication; MUSE, medigus ultrasonic surgical endostapler; PPI, proton pump inhibitor.

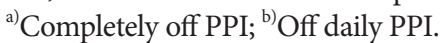

tional ARS, making them an attractive option for patients with GERD. Long-term follow-up data with evidence of durable response are available for RFA (Stretta) and emerging for transoral fundoplication techniques as well (TIF and MUSE) (Table 2). However, certain drawbacks with EARMs are noteworthy. First, these devices have been tried in select patients with minimal esophageal inflammation and small hiatus hernia. Second, although symptom response is reasonably good, objective data (like EAET) are less impressive. The current literature suggests that EARMs do reduce EAET, but often do not normalize the same. Normalization of EAET is no doubt a difficult goal to achieve, but cannot be ignored due to potential long-term consequences like Barrett's esophagus and esophageal adenocarcinoma. Similarly, the need of PPI use is reduced but not eliminated completely in substantial proportion of patients undergoing endoscopic therapy. Lastly, long-term data with some of the recently introduced EARMs are not sufficient and comparative studies between different endoscopic modalities are lacking. Therefore, the best EARM is not known (Table 2).

The definition and measures to analyse efficacy have been variable in different studies. They must be standardized to compare results between different studies or different modalities. Failure to normalize EAET or complete elimination of daily PPI usage may be regarded as therapeutic failure. On the other hand, reduction in EAET and elimination of daily PPI 
usage or reduction in dosage of PPIs after endotherapy may be regarded as successful outcome. This is exemplified by the contrasting results between two recently published meta-analyses where the first one depicted good outcomes with RFA, ${ }^{20}$ whereas the latter published meta-analysis concluded no benefit over sham procedure. ${ }^{22}$

\section{ENDOTHERAPY FOR GERD: 'OPTIMIZING' THE 'OUTCOMES'}

The outcomes with EARMs have improved, and adverse events reduced as a result of modification of techniques as well as up-gradation of available devices. Increasing the number of fasteners and plication implants have been clearly shown to improve results with TIF and EFTP, respectively. ${ }^{35,37}$ Likewise, allowing second session of RFA augmented the results of Stretta in a randomized study. ${ }^{15}$ Using a modified technique resulted in minimization of therapeutic misadventure with ultrasonic endostapler device. ${ }^{41}$ Further optimization of endoscopic devices and procedural techniques should enhance the outcomes with EARMs in the future.

In addition to the technique and devices, pre-procedure evaluation and careful patient selection is of paramount importance to obtain optimal results with EARMs. Minimum pre-procedure work up should include an esophagogastroduodenoscopy, $\mathrm{pH}$-impedance analysis, and esophageal manometry. Patients with large hiatal hernia $(>2 \mathrm{~cm}$ ), severe esophagitis (grades $\mathrm{C}$ and $\mathrm{D}$ ), Barrett's esophagus, negative $\mathrm{pH}$-impedance analysis, and ineffective esophageal peristalsis may not be suitable candidates for EARMs.

\section{CONCLUSIONS}

PPIs remain the cornerstone of medical management of GERD, and EARMs are not meant to replace PPIs altogether. They may bridge the unmet gap between PPIs and ARS. However, more studies with long-term follow-up and randomized comparisons are required to establish the role of EARMs in the management of GERD. Studies assessing the predictive factors for response or non-response to EARMs will help in minimizing failures and maximizing efficacy.

\section{Conflicts of Interest}

The authors have no financial conflicts of interest.

\section{REFERENCES}

1. El-Serag HB, Sweet S, Winchester CC, Dent J. Update on the epidemi- ology of gastro-oesophageal reflux disease: a systematic review. Gut 2014;63:871-880.

2. Katz PO, Gerson LB, Vela MF. Guidelines for the diagnosis and management of gastroesophageal reflux disease. Am J Gastroenterol 2013;108:308-328.

3. Lazarus B, Chen Y, Wilson FP, et al. Proton pump inhibitor use and the risk of chronic kidney disease. JAMA Intern Med 2016;176:238-246.

4. Abraham NS. Proton pump inhibitors: potential adverse effects. Curr Opin Gastroenterol 2012;28:615-620.

5. Schoenfeld AJ, Grady D. Adverse effects associated with proton pump inhibitors. JAMA Intern Med 2016;176:172-174.

6. Broeders JA, Rijnhart-de Jong HG, Draaisma WA, Bredenoord AJ, Smout AJ, Gooszen HG. Ten-year outcome of laparoscopic and conventional nissen fundoplication: randomized clinical trial. Ann Surg 2009;250:698-706.

7. Du X, Hu Z, Yan C, Zhang C, Wang Z, Wu J. A meta-analysis of long follow-up outcomes of laparoscopic Nissen (total) versus Toupet (270 degrees ) fundoplication for gastro-esophageal reflux disease based on randomized controlled trials in adults. BMC Gastroenterol 2016;16:88.

8. Galmiche JP, Hatlebakk J, Attwood S, et al. Laparoscopic antireflux surgery vs esomeprazole treatment for chronic GERD: the LOTUS randomized clinical trial. JAMA 2011;305:1969-1977.

9. Ganz RA, Peters JH, Horgan S, et al. Esophageal sphincter device for gastroesophageal reflux disease. N Engl J Med 2013;368:719-727.

10. Zhang H, Dong D, Liu Z, He S, Hu L, Lv Y. Revaluation of the efficacy of magnetic sphincter augmentation for treating gastroesophageal reflux disease. Surg Endosc 2016;30:3684-3690.

11. Bauer M, Meining A, Kranzfelder M, et al. Endoluminal perforation of a magnetic antireflux device. Surg Endosc 2015;29:3806-3810.

12. Kim MS, Holloway RH, Dent J, Utley DS. Radiofrequency energy delivery to the gastric cardia inhibits triggering of transient lower esophageal sphincter relaxation and gastroesophageal reflux in dogs. Gastrointest Endosc 2003;57:17-22.

13. Tam WC, Schoeman MN, Zhang Q, et al. Delivery of radiofrequency energy to the lower oesophageal sphincter and gastric cardia inhibits transient lower oesophageal sphincter relaxations and gastro-oesophageal reflux in patients with reflux disease. Gut 2003;52:479-485.

14. Arts J, Bisschops R, Blondeau K, et al. A double-blind sham-controlled study of the effect of radiofrequency energy on symptoms and distensibility of the gastro-esophageal junction in GERD. Am J Gastroenterol 2012;107:222-230.

15. Aziz AM, El-Khayat HR, Sadek A, et al. A prospective randomized trial of sham, single-dose Stretta, and double-dose Stretta for the treatment of gastroesophageal reflux disease. Surg Endosc 2010;24:818-825.

16. Dughera L, Rotondano G, De Cento M, Cassolino P, Cisarò F. Durability of Stretta radiofrequency treatment for GERD: results of an 8-year follow-up. Gastroenterol Res Pract 2014;2014:531907.

17. Corley DA, Katz P, Wo JM, et al. Improvement of gastroesophageal reflux symptoms after radiofrequency energy: a randomized, sham-controlled trial. Gastroenterology 2003;125:668-676.

18. Coron E, Sebille V, Cadiot G, et al. Clinical trial: radiofrequency energy delivery in proton pump inhibitor-dependent gastro-oesophageal reflux disease patients. Aliment Pharmacol Ther 2008;28:1147-1158.

19. Noar M, Squires P, Noar E, Lee M. Long-term maintenance effect of radiofrequency energy delivery for refractory GERD: a decade later. Surg Endosc 2014;28:2323-2333.

20. Perry KA, Banerjee A, Melvin WS. Radiofrequency energy delivery to the lower esophageal sphincter reduces esophageal acid exposure and improves GERD symptoms: a systematic review and meta-analysis. Surg Laparosc Endosc Percutan Tech 2012;22:283-288.

21. Auyang ED, Carter P, Rauth T, Fanelli RD; SAGES Guidelines Committee. SAGES clinical spotlight review: endoluminal treatments for gastroesophageal reflux disease (GERD). Surg Endosc 2013;27:2658-2672.

22. Lipka S, Kumar A, Richter JE. No evidence for efficacy of radiofrequency ablation for treatment of gastroesophageal reflux disease: a systemat- 
ic review and meta-analysis. Clin Gastroenterol Hepatol 2015;13:10581067.e1.

23. Richardson WS, Stefanidis D, Fanelli RD. Society of American Gastrointestinal and Endoscopic Surgeons response to "no evidence for efficacy of radiofrequency ablation for treatment of gastroesophageal reflux disease: a systematic review and meta-analysis". Clin Gastroenterol Hepatol 2015;13:1700-1701.

24. Liang WT, Yan C, Wang ZG, et al. Early and midterm outcome after laparoscopic fundoplication and a minimally invasive endoscopic procedure in patients with gastroesophageal reflux disease: a prospective observational study. J Laparoendosc Adv Surg Tech A 2015;25:657-661.

25. Yan C, Liang WT, Wang ZG, et al. Comparison of Stretta procedure and toupet fundoplication for gastroesophageal reflux disease-related extra-esophageal symptoms. World J Gastroenterol 2015;21:12882-12887.

26. Liang WT, Wu JM, Wang F, Hu ZW, Wang ZG. Stretta radiofrequency for gastroesophageal reflux disease-related respiratory symptoms: a prospective 5-year study. Minerva Chir 2014;69:293-299.

27. Zhang C, Wu J, Hu Z, et al. Diagnosis and anti-reflux therapy for GERD with respiratory symptoms: a study using multichannel intraluminal impedance-pH monitoring. PLoS One 2016;11:e0160139.

28. Pandolfino JE, Krishnan K. Do endoscopic antireflux procedures fit in the current treatment paradigm of gastroesophageal reflux disease? Clin Gastroenterol Hepatol 2014;12:544-554.

29. Hunter JG, Kahrilas PJ, Bell RC, et al. Efficacy of transoral fundoplication vs omeprazole for treatment of regurgitation in a randomized controlled trial. Gastroenterology 2015;148:324-333.e5.

30. Trad KS, Barnes WE, Simoni G, et al. Transoral incisionless fundoplication effective in eliminating GERD symptoms in partial responders to proton pump inhibitor therapy at 6 months: the TEMPO Randomized Clinical Trial. Surg Innov 2015;22:26-40.

31. Trad KS, Simoni G, Barnes WE, et al. Efficacy of transoral fundoplication for treatment of chronic gastroesophageal reflux disease incompletely controlled with high-dose proton-pump inhibitors therapy: a randomized, multicenter, open label, crossover study. BMC Gastroenterol 2014;14:174.

32. Håkansson B, Montgomery M, Cadiere GB, et al. Randomised clinical trial: transoral incisionless fundoplication vs. sham intervention to control chronic GERD. Aliment Pharmacol Ther 2015;42:1261-1270.

33. Testoni PA, Mazzoleni G, Testoni SG. Transoral incisionless fundoplication for gastro-esophageal reflux disease: techniques and outcomes. World J Gastrointest Pharmacol Ther 2016;7:179-189.

34. Huang $\mathrm{X}$, Chen S, Zhao H, et al. Efficacy of transoral incisionless fundoplication (TIF) for the treatment of GERD: a systematic review with meta-analysis. Surg Endosc 2016 Aug 5 [Epub]. http://dx.doi. org/10.1007/s00464-016-5111-7.

35. Testoni PA, Testoni S, Mazzoleni G, Vailati C, Passaretti S. Long-term efficacy of transoral incisionless fundoplication with Esophyx (Tif 2.0) and factors affecting outcomes in GERD patients followed for up to 6 years: a prospective single-center study. Surg Endosc 2015;29:2770-2780.

36. Toomey P, Teta A, Patel K, Ross S, Sukharamwala P, Rosemurgy AS. Transoral incisionless fundoplication: is it as safe and efficacious as a Nissen or Toupet fundoplication? Am Surg 2014;80:860-867.

37. Bell RC, Fox MA, Barnes WE, et al. Univariate and multivariate analyses of preoperative factors influencing symptomatic outcomes of transoral fundoplication. Surg Endosc 2014;28:2949-2958.

38. Witteman BP, Kessing BF, Snijders G, Koek GH, Conchillo JM, Bouvy ND. Revisional laparoscopic antireflux surgery after unsuccessful endoscopic fundoplication. Surg Endosc 2013;27:2231-2236.

39. Jain D, Singhal S. Transoral incisionless fundoplication for refractory gastroesophageal reflux disease: where do we stand? Clin Endosc 2016;49:147-156.

40. Zacherl J, Roy-Shapira A, Bonavina L, et al. Endoscopic anterior fundoplication with the Medigus Ultrasonic Surgical Endostapler (MUSE) for gastroesophageal reflux disease: 6-month results from a multi-center prospective trial. Surg Endosc 2015;29:220-229.

41. Kim HJ, Kwon CI, Kessler WR, et al. Long-term follow-up results of endoscopic treatment of gastroesophageal reflux disease with the MUSE endoscopic stapling device. Surg Endosc 2016;30:3402-3408.

42. Gweon TG, Matthes K. Prospective, randomized ex vivo trial to assess the ideal stapling site for endoscopic fundoplication with medigus ultrasonic surgical endostapler. Gastroenterol Res Pract 2016;2016:3161738.

43. Pace F, Costamagna G, Penagini R, Repici A, Annese V. Review article: endoscopic antireflux procedures: an unfulfilled promise? Aliment Pharmacol Ther 2008;27:375-384.

44. Koch OO, Kaindlstorfer A, Antoniou SA, Spaun G, Pointner R, Swanstrom LL. Subjective and objective data on esophageal manometry and impedance $\mathrm{pH}$ monitoring 1 year after endoscopic full-thickness plication for the treatment of GERD by using multiple plication implants. Gastrointest Endosc 2013;77:7-14.

45. von Renteln D, Schiefke I, Fuchs KH, et al. Endoscopic full-thickness plication for the treatment of gastroesophageal reflux disease using multiple Plicator implants: 12-month multicenter study results. Surg Endosc 2009;23:1866-1875.

46. von Renteln D, Schiefke I, Fuchs KH, et al. Endoscopic full-thickness plication for the treatment of GERD by application of multiple Plicator implants: a multicenter study (with video). Gastrointest Endosc 2008;68:833-844.

47. Satodate H, Inoue H, Fukami N, Shiokawa A, Kudo SE. Squamous reepithelialization after circumferential endoscopic mucosal resection of superficial carcinoma arising in Barrett's esophagus. Endoscopy 2004;36:909-912.

48. Inoue $\mathrm{H}$, Ito $\mathrm{H}$, Ikeda $\mathrm{H}$, et al. Anti-reflux mucosectomy for gastroesophageal reflux disease in the absence of hiatus hernia: a pilot study. Ann Gastroenterol 2014;27:346-351 